\title{
Convergent validity of the Occupational Therapy Adult Perceptual Screening Test (OT-APST) with two other cognitive-perceptual tools in a South African context
}

\author{
Fadzai Razemba, BSc OT University of Zimbabwe, MSc OT University of the Witwatersrand \\ Occupational Therapist, Ministry of Health and Social Services, Namibia
}

Lizelle Jacobs, B OT UP MSc OT Brunel University London

Lecturer, Department of Occupational Therapy, School of Therapeutic Sciences, Faculty of Health Sciences, University of the Witwatersrand

\section{Denise Franzsen, BSc OT (Wits), MSc OT (Wits), DHT UP}

Senior Lecturer, University of the Witwatersrand

Background and aim: Occupational therapists working in the field of neuro-rehabilitation need to use screening tools which demonstrate validity and reliability to correctly identify patients with cognitive-perceptual impairments. The Occupational Therapy Adult Perceptual Screening Test (OT-APST) is a screening tool which was developed to identify patients with visual perceptual problems and apraxia following a stroke or other forms of acquired brain injury. Other instruments commonly used in South Africa are the Loewenstein Occupational Therapy Cognitive Assessment (LOTCA) and the Rivermead Perceptual Assessment Battery (RPAB). These tools evaluate similar constructs such as visual agnosia, body scheme, unilateral neglect and constructional skills but are too lengthy to use as screening tools.

The aim of the study was to determine the convergent validity of the OT-APST with two other cognitive-perceptual tools, namely the Dynamic Loewenstein Occupational Therapy Cognitive Assessment (DLOTCA) and the RPAB when administered to patients with a primary diagnosis of stroke.

Method: A quantitative cross-sectional study was conducted on a sample of 32 participants with a primary diagnosis of stroke. Participants completed the three tools and subscales were compared with the DLOTCA cognitive areas and the RPAB items.

Results: Five subscales of the OT-APST had significant correlations with similar DLOTCA and/or the RPAB subscales. Only the Apraxia subscale did not correlate with the referencing tools.

Conclusion: This study provides further evidence of the convergent validity of the OT-APST when compared to the DLOTCA and RPAB. Although the OT-APST was standardised on an Australian population, it proved to be another option of a visual perceptual screening tool to identifying visual perceptual problems in patients with stroke in South Africa.

Key words: Cognitive-perceptual, stroke, convergent validity, Occupational Therapy Adult Perceptual Screening Test (OT-APST), Dynamic Loewenstein Occupational Therapy Cognitive Assessment (DLOTCA), Rivermead Perceptual Assessment Battery (RPAB)

\section{INTRODUCTION}

Non-communicable diseases are a major concern worldwide in terms of mortality and morbidity'. The World Health Organisation predicts that by 2030 most people will die from non-communicable diseases such as heart disease, stroke, cancer, diabetes, and chronic respiratory diseases ${ }^{2}$. Similarly in South Africa (SA), non-communicable diseases have been reported as one of the main causes of death $^{3}$ of which Nojilana, Bradshaw, Pillay-van Wyk et $\mathrm{al}^{3}$ found that, stroke was the number one cause ${ }^{3}$. The prevalence of stroke for people from I 5 years and older, is 3 for every I 000 in South Africa ${ }^{4}$.

It has been found that one in 500 stroke patients will require help with at least one activity of daily living (ADL) ${ }^{4}$, and this may be as a result of motor, sensory, cognitive or perceptual deficits ${ }^{5}$. Srikanth, et al. ${ }^{6}$, found that $35,2 \%$ of patients had cognitive impairments following a stroke. Cognitive impairments, often associated with stroke, include poor attention, orientation, spatial abilities and executive abilities ${ }^{6,7}$. Cognition further plays a major role in visual perception ${ }^{8}$. As part of a holistic rehabilitation programme, there is a need to screen and assess for cognitive problems ${ }^{9}$ as well as visual perception ${ }^{10}$ in an effort to achieve independence following a stroke.

A number of measuring instruments are available that include both cognitive and visual perceptual skills such as visuospatial abilities $^{7}$. In South Africa, occupational therapists often use the Loewenstein Occupational Therapy Cognitive Assessment (LOTCA)" which is considered the gold standard in terms of visual perceptual tests ${ }^{12}$ and the Rivermead Perceptual Assessment Battery ${ }^{13}$. However, these tools are time consuming, costly and have not been standardised on the SA population. The tests are costly as they increase the number of assessment sessions required for completion.

Screening tools have been documented to be easier, faster and less expensive to use in comparison with in-depth assessments ${ }^{14,15}$. The therapist uses the information gathered to determine which patients need thorough assessments therefore making it more 
cost-effective for patients. It is furthermore time efficient for the occupational therapist to quickly identify which patients require more help, particularly when the therapist has several patients to manage. Further, occupational therapists need to use valid and reliable screening tools in order to correctly identify patients with cognitive and perceptual impairments ${ }^{16}$ and to substantiate the need for in-depth assessments and guide appropriate intervention 12,17 .

The aim of this study was to investigate the convergent validity of the Occupational Therapy Adult Perceptual Screening Test (OTAPST $)^{18}$ with two other cognitive-perceptual tools used in South Africa to inform the suitability of a cognitive-perceptual screening tool for therapists practising in the South African context.

\section{LITERATURE REVIEW}

\section{The OT-APST}

The OT-APST was developed in response to a need for a comprehensive visual perception screening tool, since available instruments in occupational therapy were too lengthy and these tools were designed to be administered in their entirety for validity reasons ${ }^{18}$. The OT-APST was developed in Queensland, Australia for the purpose of identifying patients with visual perceptual problems and apraxia following a stroke or other forms of acquired brain injury (from 16 years of age) ${ }^{16,19}$. It has a total of 25 items under seven subscales with several of the items contributing to more than one subscale $^{19}$. The OT-APST can be administered in approximately 20-25 minutes and it should also be completed in its entirety to maintain its validity properties ${ }^{19}$. Interpretation of results requires comparing the scores to normative data and the results will indicate whether there is need for more detailed assessments as well as guide treatment planning ${ }^{19}$. Table I provides a description of the seven functions evaluated by the test.

Table I: A description of the Occupational Therapy Adult Perceptual Screening Test (OT-APST) Subscales ${ }^{18,20}$

\begin{tabular}{|l|l|}
\hline OT-APST Subscales & Description \\
\hline Agnosia & $\begin{array}{l}\text { The inability to recognise objects, people, } \\
\text { sounds, shapes or smells. This includes items } \\
\text { that evaluate colour agnosia, object agnosia, } \\
\text { figure-ground, shape constancy, and alexia } \\
\text { (reading difficulties). }\end{array}$ \\
\hline Body Scheme & $\begin{array}{l}\text { The awareness of one's body. This includes } \\
\text { items where the participant must point to body } \\
\text { parts on himself or herself, point to body parts } \\
\text { on the assessing therapist, discriminate between } \\
\text { left and right sides of his or her body, and follow } \\
\text { directions related to position in space. }\end{array}$ \\
\hline Unilateral Neglect & $\begin{array}{l}\text { A deficit in attention or awareness to one side. } \\
\text { This is assessed via a clock drawing, telling the } \\
\text { time on the clock face, copying a picture of a } \\
\text { house, reading and writing. }\end{array}$ \\
\hline Constructional Skills & $\begin{array}{l}\text { The visuospatial and visuoconstructional } \\
\text { skills required to draw and construct shapes } \\
\text { and copy designs. This is assessed by two- } \\
\text { dimensional and three-dimensional construction } \\
\text { tasks using plain blocks. }\end{array}$ \\
\hline Acalculia & $\begin{array}{l}\text { Reading, writing, arithmetic, reading the time } \\
\text { and using a stapler. }\end{array}$ \\
\hline Functional Skills & $\begin{array}{l}\text { An inability to carry out once learnt and } \\
\text { purposeful movements, including writing, using } \\
\text { a pen for writing, using a stapler, and waving } \\
\text { with left and right hands. }\end{array}$ \\
$\begin{array}{l}\text { An acquired difficulty in carrying out simple } \\
\text { maths calculations. This includes the completion } \\
\text { of addition and subtraction questions. }\end{array}$ \\
\hline tang
\end{tabular}

In a study by Cooke et al. ${ }^{20}$, to determine the convergent validity of the OT-APST, results were compared and correlated with the LOTCA and the LOTCA-G (Geriatric) $)^{21}$ which were used as a "gold standard" 12 . Cooke et al. found that the LOTCA had several subscales which could be compared to the OT-APST and Spearman's rho correlations were used to determine convergent validity between these items which showed statistically significant correlations with $p<0.0 \mathrm{I}^{20}$. In the same research on the OTAPST and LOTCA/LOTCA-G, Cooke et.al, did not compare the OT-APST Acalculia and Functional skills subscales to the LOTCA as the LOTCA did not have an item evaluating arithmetical skills or functional skills ${ }^{\prime 2}$. Although the LOTCA does not have a subscale specifically for unilateral neglect, the authors added the LOTCA Puzzle and Clock items to their analysis as they were thought to be comparable with the OT-APST Unilateral Neglect subscale ${ }^{19}$. They also found the highest correlations to be with the Constructional Skills $(r h o=0.802)$ and Unilateral Neglect subscales $(r h o=0.640)^{12}$.

The majority of the research on the psychometric properties of the OT-APST had been done in Australia by the author of the test, Cooke, who reported that the OT-APST demonstrated criterion, ecological and construct validity ${ }^{12,16}$. Validity is described as the appropriateness of a test and indicates whether it tests what it purports to test ${ }^{22}$. The results on the validity of the OT-APST were contradicted by Brown, Mapleston and Nairn ${ }^{20}$ who found that the OT-APST did not converge to where it was theoretically expected, when compared to the Neurobehavioural Cognitive Status Examination (Cognistat) ${ }^{23}$ and the Developmental Test of Visual Perception- Adolescent and Adult (DTVP-A) ${ }^{20}$.

In the study done by Brown et al. ${ }^{20}$, the researchers used the Cognistat and DTVP-A to determine the convergent validity of the OT-APST by using Spearman's rho correlations. While the DTVP-A is a test specifically for visual perception, the Cognistat is a cognitive screening test and it has a few subscales which address visual perception as described by Brown et al. ${ }^{20}$. Spearman's rho correlations were used between subscales of the OT-APST, the Cognistat and the DTVP-A and the raw scores from all three tools were used to calculate the correlations. The OT-APST did not correlate with the Cognistat, as expected. Only three of the ten Cognistat subscales correlated significantly with two OT-APST subscales ${ }^{20}$. The Cognistat Constructional Ability and Calculation significantly correlated with the OT-APST Body Scheme while the Cognistat Memory subscale significantly correlated with the OT-APST Functional Skills subscales ${ }^{20}$. This might be attributed to the fact that the Cognistat is essentially a cognitive screening tool rather than a perceptual tool. It must further be noted that the level of significance was set at 0.4 when rounded up despite having a small sample of 32 participants and the significant correlations between the OT-APST and the Cognistat ranged from 0.357 to $0.38 \mathrm{I} p<0.05^{20}$.

Three of the DTVP-A items namely Figure-Ground, Visual Motor Search and the Visual Closure all significantly correlated with OT-APST Body Scheme subscale with correlations ranging from 0.372 to $0.422 p<0.05$. These results revealed that only one subscale from the OT-APST significantly correlated with half of the DTVP-A subscales ${ }^{20}$. This might be interpreted to mean that the OT-APST does not evaluate what it purports to evaluate and can therefore not be used as a screening tool in South Africa.

\section{Loewenstein Occupational Therapy Cognitive Assessment (LOTCA)}

The initial LOTCA was developed in Israel ${ }^{10}$ and the main purpose was to assess the cognitive abilities of patients following head injuries ${ }^{10}$. The LOTCA has 26 items grouped into six cognitive subscales including: Orientation, Visual perception, Spatial perception, Visuo- 
motor organisations, Motor praxis and Thinking operations ${ }^{24}$. The Dynamic Loewenstein Occupational Therapy Cognitive Assessment $(\text { DLOTCA })^{25}$ is the latest version of the LOTCA and was developed to determine the level of functioning for patients (between the ages of 18 and 69 years) in the different subscales as well as to determine the potential of the patient to learn ${ }^{25}$ so that occupational therapy treatment can be planned accordingly ${ }^{24}$. The validity of the LOTCA was already established and there is no mention of the DLOTCA going through validity testing in the manual ${ }^{25}$.

Dynamic assessments are based on identifying the zone of proximal development and the DLOTCA has mediation and cueing included within the evaluation process to determine the potential of the patient to learn ${ }^{25}$. The mediation is used when a patient gets an item wrong, the patient is cued and then scored according to how much mediation was required ${ }^{25}$. The 'after mediation' score is obtained after the therapist has given the patient cues on the failed item. The mediation cues are based on Toglia's guidelines ${ }^{26}$. The amount of mediation will determine the length of administration, it may take one to two hours and it may be done in two sessions ${ }^{25}$. $V$ isual perception and cognition are difficult to separate and in both the LOTCA and the DLOTCA, visual perception is considered a primary cognitive function ${ }^{25}$.

The results in the DLOTCA are not compared with a normative sample and results from a dynamic tool are considered to be more ecologically valuable as compared to static tools ${ }^{26}$. The DLOTCA which was used in this research, has 28 items grouped under seven subscales which include the Orientation, Awareness, Visual Perception, Spatial Perception, Praxis, Visuomotor Construction and the Thinking Operations. The subscales are described in Table II.

Of the seven cognitive domains, orientation and awareness are not dynamic (they do not have an 'after mediation' score). The DLOTCA demonstrated good interrater reliability with high correlations $(r=0.98)$ and discriminant validity was determined between stroke patients and normal adults ${ }^{25}$. The DLOTCA was used on the assumption that the previous LOTCA was considered a gold standard ${ }^{12}$.

\section{Rivermead Perceptual Assessment Battery}

The Rivermead Perceptual Assessment Battery (RPAB) was developed in the United Kingdom to assess visual perception in patients after stroke and it may be used to monitor progress ${ }^{13}$. It has a total of 16 items grouped into the eight categories of: Form Constancy, Colour Constancy, Sequencing, Object Completion, Figure Ground Discrimination, Body Image, Inattention and Spatial Awareness ${ }^{13}$. The categories are described in Table III. The tool takes about 45 to 60 minutes to administer on normal subjects, and can be administered in two sessions ${ }^{13}$. Results from the RPAB are compared to normative data (aged 16 to 69). RPAB has demonstrated test- retest reliability with II out of 16 subscales having a correlation above $0.5^{13}$.

Both the DLOTCA and RPAB are lengthy assessments and require at least 45 minutes to 2 hours to complete which makes them too long to be used as screening tools. Considering the po-

Table II: A description of the Dynamic Loewenstein Occupational Therapy Cognitive Assessment (DLOTCA) Cognitive Areas ${ }^{25}$

\begin{tabular}{|l|l|}
\hline DLOTCA Cognitive Areas & Description \\
\hline Orientation & The assessor asks questions on orientation of place and of time. \\
\hline Awareness & Awareness of reason of hospitalisation and of cognitive abilities \\
\hline Visual Perception & These skills are evaluated using: Object Identification, Figure-Ground and Object Identification items. \\
\hline Spatial Perception & $\begin{array}{l}\text { The ability to perceive the relationship between objects or objects and self includes: Directions on client's } \\
\text { body, Spatial relations on a picture, Spatial relations between client and Objects in near space items. }\end{array}$ \\
\hline Praxis & $\begin{array}{l}\text { Being able to perform skilled movements and it includes: Motor Imitation, Utilisation of Objects, Symbolic } \\
\text { Actions items. }\end{array}$ \\
\hline Visuomotor Construction & $\begin{array}{l}\text { This is a motor perceptual skill which includes: Copy Geometric Forms, 2D Construction, Pegboard, Coloured } \\
\text { Block Design, Plain Block Design, Puzzle, Clock items. }\end{array}$ \\
\hline Thinking Operations & $\begin{array}{l}\text { Conceptualisation is assessed using Categorisation, Riska Object Classification, Picture Sequence, Geometric } \\
\text { Sequence, Verbal Mathematical Questions items. }\end{array}$ \\
\hline
\end{tabular}

Table III: A description of the Rivermead Perceptual Assessment Battery (RPAB) Categories ${ }^{13}$

\begin{tabular}{|l|l|}
\hline RPAB Category & Description \\
\hline Form Constancy & $\begin{array}{l}\text { Constancy refers to how an object remains unchanged despite environmental changes, orientation, angle } \\
\text { or lighting 27. This is assessed by matching objects in pictures and real objects. } \\
\text { Items: Picture Matching, Object Matching and Size Recognition. }\end{array}$ \\
\hline Colour Constancy & $\begin{array}{l}\text { Being able to identify different shades of the same colour. } \\
\text { Item: Colour Matching. }\end{array}$ \\
\hline Sequencing & $\begin{array}{l}\text { Being able to put a series of pictures in order. } \\
\text { Item: Series and Sequencing Pictures. }\end{array}$ \\
\hline Object Completion & $\begin{array}{l}\text { Being able to complete given pictures. } \\
\text { Items: Animal Halves and Missing Article. }\end{array}$ \\
\hline Body Image & $\begin{array}{l}\text { Identifying objects against a competing background. } \\
\text { Item: Figure-Ground. }\end{array}$ \\
\hline Inattention & $\begin{array}{l}\text { Being able to correctly assemble a body and being able to imitate postures. } \\
\text { Items: Body Image and Body Image - Self Identification. }\end{array}$ \\
\hline Spatial Awareness & $\begin{array}{l}\text { Assessed by ability to cross the midline whilst copying shapes, words and cancelling a letter. } \\
\text { Items: R/L Copying Shapes, R/L Copying Words and Cancellation. }\end{array}$ \\
\hline
\end{tabular}


Table IV: Comparable items from the Occupational Therapy Adult Perceptual Screening Test (OT-APST), Rivermead Perceptual Assessment Battery (RPAB) and the Dynamic Loewenstein Occupational Therapy Cognitive Assessment (DLOTCA)

\begin{tabular}{|c|c|c|c|}
\hline \multirow{2}{*}{$\begin{array}{l}\text { OT-APST Subscales } \\
\text { Subscales }\end{array}$} & \multicolumn{3}{|c|}{ Tests } \\
\hline & OT-APST & DLOTCA & RBAB \\
\hline Agnosia & $\begin{array}{l}\text { Colour Naming, Object Name, } \\
\text { Figure-Ground, Shape Constancy, } \\
\text { Reading }\end{array}$ & $\begin{array}{l}\text { Visual perception: Object Identification, } \\
\text { Figure-Ground and Object Constancy }\end{array}$ & $\begin{array}{l}\text { Picture Matching, Object } \\
\text { Matching, Colour Matching, Size } \\
\text { Recognition, Figure-Ground }\end{array}$ \\
\hline Body Scheme & $\begin{array}{l}\text { Body Parts-Self, Body Parts-Therapist, } \\
\text { Left/Right on Self, Directions/Positions }\end{array}$ & $\begin{array}{l}\text { Spatial perception: Directions on } \\
\text { Client's body, Spatial Relations between } \\
\text { Client and Objects in Near space, } \\
\text { Spatial Relations on a Picture }\end{array}$ & $\begin{array}{l}\text { Body Image Self-identification, } \\
\text { Body Image. }\end{array}$ \\
\hline Unilateral Neglect & $\begin{array}{l}\text { Clock, House, Hand Writing, Reading, } \\
\text { Telling Time }\end{array}$ & Puzzle, Clock & $\begin{array}{l}\text { R/L Copying Words and Shapes, } \\
\text { Cancellation }\end{array}$ \\
\hline Constructional skills & $\begin{array}{l}\text { Clock, House, 2D Construction, 3D } \\
\text { Construction }\end{array}$ & $\begin{array}{l}\text { Geometric Forms, 2D, Pegboard, } \\
\text { Coloured Block Design, Puzzle, Clock } \\
\text { Drawing }\end{array}$ & $\begin{array}{l}\text { 3D Copying Selection, Cube } \\
\text { Copying }\end{array}$ \\
\hline Apraxia & $\begin{array}{l}\text { Facial Gesture, Wave Right Hand, } \\
\text { Wave Left Hand, Stapler Manipulation, } \\
\text { Pen Use, Handwriting }\end{array}$ & $\begin{array}{l}\text { Motor Imitation, Utilisation of Objects, } \\
\text { Symbolic Action }\end{array}$ & No similar item \\
\hline Acalculia & Acalculia & Verbal Mathematical Questions & No similar item \\
\hline
\end{tabular}

tential benefits of a screening tool in terms of time and cost, there was a need to demonstrate and clarify the degree of convergent validity of the OT-APST as this can be a valuable screening tool for therapists in the South African context.

\section{METHOD}

A quantitative, correlational study was conducted. The aim of the study was to determine the convergent validity of the OT-APST with two other cognitive-perceptual tools used in South Africa i.e. the DLOTCA and the RPAB. A convergent validity study focuses on evaluating similarity or correlation of test results with other similar tests ${ }^{17}$.

\section{Participants}

The study population consisted of 32 in-patients selected from Charlotte Maxeke Johannesburg Academic Hospital, Life Kensington Hospital and Netcare Rehabilitation Hospital between November 2012 and April 20I3. Convenience sampling was used to select patients younger than 70 years (25 to 69 ), whose primary diagnosis was one of stroke. Patients were included in the study if they were proficient enough in English to give consent as well as understand the instructions of the assessments, had sufficient endurance and mental acuity to finish all three assessments (although the assessments were not all administered in one sitting), were able to sit for at least 30 minutes and attend to table-top activities and had functional reading abilities and the ability to use one hand for task completion (independent of hand dominance), as specified by OT-APST.

Patients were excluded if their level of consciousness prohibited completion of the assessment; if they experienced auditory/receptive language and comprehension problems that would reduce the validity of assessment; if they had a co-morbid diagnosis or preexisting diagnosis (e.g. psychosis or dementia) which would interfere with basic cognitive functioning; or a neurological or psychological event that occurred before the completion of the assessments.

\section{Measuring Instruments}

The instruments used for this study were the OT-APST, DLOTCA and the RPAB, standardised cognitive-perceptual assessment tools with manuals providing information on the administration and scoring of the tools.

The OT-APST Functional Skills subscale was not included in this study as neither the DLOTCA nor the RPAB have any functional skills items. Furthermore, while the DLOTCA is a dynamic assessment, the scores after mediation were not used in this study because both the OT-APST and the RPAB give static measures of cognitive-perceptual skills.

Prior to the collection of the data, the researcher reviewed each item on all three tools in terms of the definition, the description and related literature to determine which items measured similar constructs $^{12}$. Some of the items of the assessment tools had different names but when looking at the administration procedure, it was clear that they were measuring the same construct e.g. OT-APST Body Parts-Self item and the DLOTCA Direction on Client's Body item. These similar items for the three assessment tools are presented in Table IV. The researcher further hypothesised that these similar items should demonstrate convergent validity.

\section{Procedure}

Ethical clearance was obtained from the University of Witwatersrand Human Research Ethics Committee (Ethical clearance number MI2063I). Permission was also obtained from the: Gauteng Department of Health, Chief Executive Officer (CEO) of the Charlotte Maxeke Johannesburg Academic Hospital, the CEO of Life Kensington Hospital and the CEO of Netcare Rehabilitation Hospital. Permission was also obtained from the head of the Occupational Therapy Department at each of the hospitals. Patients were given an information sheet which they could keep and they were verbally told what the research entailed. All patients who agreed to participate were required to sign a consent form and they were assured that their information would be kept confidential.

The tests were carried out in at least two sittings, either in the patient's cubicle with the patient sitting upright on a chair or wheelchair or in some cases in a quiet room with minimal distractions. All the participating hospitals provided a quiet room for the researcher to use. To save time on moving the participant from his /her room to the allocated room, the researcher would occasionally opt to use the patient's room. Although the initial plan was to ensure that care was to be taken to replicate the previous day's activities, e.g. if the patient starts with occupational therapy the same routine would be followed, this was not always feasible because the researcher did not want to interfere with the hospital routine. In some instances, the patient was scheduled for MRI or other out-of-hospital procedures and this was beyond the control of the researcher. The researcher and assistant followed the testing procedure in the manuals for each of the tools.

The administration sequence of the three tools was randomised to reduce the test-order effect ${ }^{20}$. To further reduce bias, the researcher tested the patients using the DLOTCA and the RPAB 
while the research assistant (a final year occupational therapy student) was acquired to conduct the third test (OT-APST). The three tools were administered on each participant within a time period no greater than 72 hours (replicating the conditions of the criterion validity of OT-APST) ${ }^{16}$. The assistant and researcher did not comment on a participant's performance until all the tests had been administered.

\section{Data analysis}

Data were coded and stored as well as tabulated using Microsoft Excel and were analysed using STATISTICA version 12. Descriptive statistics were used to describe the participants' demographic data. Due to the small sample size normality could not be assumed and a non-parametric test i.e. the Spearman's rank correlation coefficient was used to correlate the data obtained from the three assessment tools. In line with Brown et al.'s study ${ }^{20}$ the raw test scores were used to calculate the correlations between the three tests. Using the correlation interpretation of strength presented by Kielhofner ${ }^{27}$ as guidelines, correlations between $0-0.2$ were deemed negligible; 0.2 - 0.4 were low; 0.4 - 0.54 were low moderate; $0.55-0.6$ were moderate; $0.6-0.8$ were high; and $0.8-1.00$ were very high. Only correlations from 0.55 - I.0 $(\mathrm{p}<0.05)$ were considered significant due to the small sample size.

\section{RESULTS}

\section{Demographic information of the participants}

Three hospitals participated in the research namely Netcare Rehabilitation Hospital which contributed fifty percent of the study sample $(n=16)$, Charlotte Maxeke Johannesburg Academic Hospital and Life Kensington Hospital each contributing twenty-five percent $(n=8$ and $n=8)$.

The participants were evenly distributed with 16 females and 16 males $(n=32)$. Most of the participants $(n=27)$ were above the age of 40 . Seventy-eight percent $(n=25)$ of the participants had a stroke on the right side of the brain, nineteen percent of the patients $(n=6)$ had a stroke on the left side but without aphasia and only three percent $(n=l)$ had a stroke in the basal ganglia.

\section{Summary of the scores of the three tests}

The mean scores and standard deviations of the participants' performance on the OT-APST, DLOTCA and RPAB are presented in Table V.

\section{OT-APST - DLOTCA correlations}

Table VI on page 8 shows the correlations between the OT-APST subscales and the DLOTCA cognitive areas. The correlations in bold indicate expected correlations according to similar constructs being tested. Five of the OT-APST subscales had moderate to very high correlations with similar construct cognitive areas of the DLOTCA. Only the OT-APST Apraxia subscale had no significant correlation with the expected Praxis cognitive area of the DLOTCA cognitive areas.

\section{OT-APST - RPAB correlations}

The correlations between the OT-APST and the RPAB are presented. The correlations in bold again indicate expected correlations according to similar constructs being tested (Table VI on page 8). The
Table V: Descriptive data for the Occupational Therapy Adult Perceptual Screening Test (OT-APST), Dynamic Loewenstein Rivermead Perceptual Assessment Battery (RPAB)

\begin{tabular}{|c|c|c|c|c|c|}
\hline $\begin{array}{l}\text { Cognitive-perceptual } \\
\text { tool item }\end{array}$ & $\begin{array}{l}\text { Mean } \\
\text { score }\end{array}$ & SD & $\begin{array}{l}\text { Minimum } \\
\text { score }\end{array}$ & $\begin{array}{l}\text { Maximum } \\
\text { score }\end{array}$ & $\begin{array}{l}\text { Cut-of } \\
\text { score }\end{array}$ \\
\hline \multicolumn{6}{|l|}{ OT-APST } \\
\hline Agnosia & 22.67 & 4.01 & 11.0 & 26.0 & 24 \\
\hline Body Scheme & 20.87 & 3.55 & 5.0 & 22.0 & 21 \\
\hline Unilateral Neglect & 9.90 & 2.68 & 3.0 & 13.0 & 12 \\
\hline Constructional Skills & 43.57 & 9.50 & 19.0 & 53.0 & 51 \\
\hline Apraxia & 9.30 & 1.12 & 6.0 & 10.0 & 9 \\
\hline Acalculia & 3.20 & 1.16 & 0 & 4.0 & 2 \\
\hline \multicolumn{6}{|l|}{ DLOTCA } \\
\hline Visual Perception & 3.50 & 0.35 & 2.33 & 4 & $\mathrm{~N} / \mathrm{A}$ \\
\hline Spatial Perception & 0.88 & 0.15 & 0.33 & 1 & $\mathrm{~N} / \mathrm{A}$ \\
\hline $\begin{array}{l}\text { Visuomotor } \\
\text { Construction }\end{array}$ & 3.59 & 1.07 & 1.29 & 5 & $\mathrm{~N} / \mathrm{A}$ \\
\hline Puzzle & 3.20 & 1.30 & I & 5 & $\mathrm{~N} / \mathrm{A}$ \\
\hline Clock & 3.57 & 1.36 & 1 & 5 & $\mathrm{~N} / \mathrm{A}$ \\
\hline Praxis & 0.88 & 0.14 & 0.33 & 1 & $\mathrm{~N} / \mathrm{A}$ \\
\hline Verbal Mathematics & 0.47 & 0.39 & 0 & 1 & $\mathrm{~N} / \mathrm{A}$ \\
\hline \multicolumn{6}{|l|}{ RPAB } \\
\hline Picture matching & 3.60 & 0.856 & I & 4 & 4 \\
\hline Object matching & 3.87 & 0.73 & 0 & 4 & 4 \\
\hline Colour matching & 10.60 & 2.89 & 3 & 12 & 12 \\
\hline Size recognition & 3.87 & 0.73 & 0 & 4 & 4 \\
\hline Figure-ground & 3.20 & 0.714 & 1 & 4 & 2 \\
\hline Body image & 8.16 & 3.37 & 0 & 12 & 10 \\
\hline R/L Shapes & 31.73 & 26.86 & 0 & 72 & 65 \\
\hline R/L Words & 17.00 & 12.06 & 0 & 32 & 30 \\
\hline Cancellation & 37.37 & 18.18 & 0 & 52 & 48 \\
\hline 3D Copying selection & 17.7 & 8.77 & 0 & 24 & 18 \\
\hline Cube copying & 36.5 & 24.74 & 0 & 72 & 54 \\
\hline \multicolumn{6}{|c|}{$\mathrm{N} / \mathrm{A}=$ not available. $\mathrm{SD}=$ standard deviation } \\
\hline
\end{tabular}

OT-APST Agnosia, Unilateral Neglect and Constructional Skills subscales had moderate to very high correlations with similar construct RPAB items (Colour Matching, Figure-Ground, Shapes Copying, Word Copying and Cube Copying). Body Scheme, Apraxia and Acalculia OT-APST subscales did not have significant correlations with any of the RPAB items. This was expected for the OT-APST Apraxia and Acalculia subscales as the RPAB does not have any items related to praxis or acalculia. The RPAB does however have Body Image and Body Image-Self Identification items which are similar constructs to the OT-APST Body Scheme subscale.

\section{DISCUSSION}

The OT-APST was developed out of the need for a screening tool ${ }^{28}$. In the South African context where therapists often have large caseloads, the OT-APST can potentially be a viable screening tool. It is however important to use screening tools that are valid and reliable in order to correctly identify patients with cognitive and perceptual impairments ${ }^{16}$. The focus of this study was to examine the convergent validity of the OT-APST by comparing it with two cognitive-perceptual tests most often used in the South African context i.e. the DLOTCA and the RPAB. 
Table VI: Correlations between performance of participants following stroke on the Occupational Therapy Adult Perceptual Screening Test (OT-APST) and the Dynamic Loewenstein Occupational Therapy Cognitive Assessment (DLOTCA)

\begin{tabular}{|c|c|c|c|c|c|c|}
\hline \multirow{2}{*}{$\begin{array}{l}\text { DLOTCA } \\
\text { Cognitive area }\end{array}$} & \multicolumn{5}{|c|}{ OT-APST subscales } & \multirow[b]{2}{*}{ Acalculia } \\
\hline & Agnosia & Body Scheme & Unilateral Neglect & Constructional Skills & Apraxia & \\
\hline Visual Perception & $0,577^{*}$ & 0,258 & 0,516 & 0,639** & 0,043 & 0,343 \\
\hline Spatial Perception & $0,591 *$ & $0,606 * *$ & $0,557^{*}$ & $0,636^{*} *$ & 0,277 & $0,742 * *$ \\
\hline Praxis & $0,664 * *$ & 0,184 & 0,484 & $0,629 * *$ & 0,436 & 0,340 \\
\hline $\begin{array}{l}\text { Visuomotor } \\
\text { Construction } \\
\text { - Puzzle } \\
\text { - Clock }\end{array}$ & $0,710 * *$ & 0,248 & $\begin{array}{c}0,590 * \\
0,55 I * \\
0,440\end{array}$ & $0,903 * * *$ & 0,382 & 0,539 \\
\hline $\begin{array}{l}\text { Verbal Mathematical } \\
\text { Questions }\end{array}$ & 0,492 & 0,348 & 0,503 & 0,460 & 0,342 & $0,690 * *$ \\
\hline
\end{tabular}

Table VII: Correlations between performance of participants following stroke on the Occupational Therapy Adult Perceptual Screening Test (OT-APST) and the Rivermead Perceptual Assessment Battery (RPAB)

\begin{tabular}{|c|c|c|c|c|c|c|}
\hline \multirow{2}{*}{ RPAB ITEMS } & \multicolumn{6}{|c|}{ OT-APST subscales } \\
\hline & Agnosia & Body Scheme & $\begin{array}{c}\text { Unilateral } \\
\text { Neglect }\end{array}$ & $\begin{array}{l}\text { Constructional } \\
\text { Skills }\end{array}$ & Apraxia & Acalculia \\
\hline Picture Matching & 0,452 & 0,231 & 0,433 & $0,589 *$ & $-0,195$ & 0,223 \\
\hline Object Matching & 0,408 & $-0,060$ & 0,415 & 0,488 & $-0,118$ & 0,032 \\
\hline Colour Matching & $0,677^{*} *$ & 0,464 & $0,545 *$ & $0,607 * *$ & $-0,121$ & 0,467 \\
\hline Size Recognition & 0,408 & $-0,06$ & 0,415 & 0,488 & 0,118 & 0,032 \\
\hline Figure-Ground & $0,578 *$ & 0,31 & $0,659 * *$ & $0,597 *$ & 0,353 & 0,159 \\
\hline Shapes Copying & $0,660 * *$ & 0,256 & $0,725 * *$ & $0,693 * *$ & 0,470 & 0,472 \\
\hline Word Copying & $0,714^{* * *}$ & 0,400 & $0,665 * *$ & $0,632 * *$ & 0,411 & 0,524 \\
\hline Cancellation & $0,639 * *$ & 0,166 & $0,5 \mid 4$ & $0,552 *$ & 0,371 & 0,3 \\
\hline 3D Copying Selection & $0,738^{* * *}$ & 0,27 & $0,58^{*}$ & $0,7^{* *}$ & 0,283 & 0,387 \\
\hline Cube Copying & 0,530 & 0,251 & 0,54 & $0,744 * *$ & 0,394 & 0,51 \\
\hline Body Image & $0,636^{* *}$ & 0,353 & $0,566 *$ & $0,728 * *$ & 0,315 & 0,265 \\
\hline $\begin{array}{l}\text { Body Image-Self } \\
\text { Identification }\end{array}$ & 0,456 & $-0,02$ & 0,39 & $0,624 * *$ & 0,30 & 0,134 \\
\hline \multicolumn{7}{|c|}{ Spearman's rho used to measure correlation; $0.05<\mathrm{p}$-value; *moderate correlation, ${ }^{*} *$ high correlation, ${ }^{*} * *$ very high correlation. } \\
\hline \multicolumn{7}{|c|}{ Correlations in bold were the expected correlations according to Table IV. } \\
\hline
\end{tabular}

The convergent validity of the OT-APST will be discussed under the individual OT-APST subscales.

\section{Agnosia}

The Agnosia subscale of the OT-APST significantly correlated with the following DLOTCA domains: Visual Perception cognitive area $($ rho $=0,577)$, Spatial Perception cognitive area $(r h o=0,59 \mathrm{I})$, Praxis $(r h o=0,664)$ and Visuomotor Construction (rho $=0,710)$. These findings were expected since these individual items assess similar constructs. The results also correlate with another study by Cooke et al. ${ }^{13}$, when the researchers also found that the LOTCA Visual perception domain significantly correlated with the OT-APST Agnosia subscale $(r h o=0,508 p<0.0 I)$. In contrast Brown et al. ${ }^{20}$ found, the OT-APST Agnosia subscale did not significantly correlate with the Neurobehavioural Cognitive Status Examination (Cognistat) or the Developmental Test of Visual Perception-Adolescent and Adult (DTVP-A) with correlations of 0.324 and below. This was possibly due to the fact that the three tools evaluated different constructs ${ }^{20}$.

For this study (see Table IV) the RPAB Picture Matching, Object Matching, Colour Matching, Size Recognition and Figure-Ground items were grouped under agnosia and it was therefore expected to correlate with the OT-APST Agnosia subscale. The OT-APST Agnosia subscale and RPAB Colour Matching (rho $=0,676)$ and Figure-Ground $(\mathrm{rho}=0,577)$ items had strong and moderate correlations respectively while the RPAB Picture Matching $(r h o=0,452)$, Object Matching (rho $=0,408)$ and Size Recognition (rho $=0,408)$ items had low correlations. It is possible that not adding the RPAB items, to get a composite score, may contribute to the reasons why the RPAB agnosia items did not significantly correlate with the OT-APST Agnosia subscale. Further investigation is however needed to ascertain why the two tools have poor correlations on similar agnosia items.

\section{Body Scheme}

The OT-APST Body Scheme subscale was compared with the DLOTCA Spatial Perception cognitive area because the two cognitive areas had comparable items i.e. Directions on Client's Body, Spatial Relations between Client and Objects in Near Space, and Spatial Relations on a Picture. As expected, the DLOTCA Spatial Perception strongly correlated with the OT-APST Body scheme 
(rho $=0,606)$. This is consistent with the results found in Cooke et al.'s ${ }^{13}$ study where the OT-APST Body Scheme significantly correlated with the LOTCA Spatial Perception subscale.

The OT-APST Body Scheme subscale did not correlate with comparable items from the RPAB i.e. Body lmage ( $r$ o $=0,353$ ) and Body Image - Self-Identification ( $r$ o $=-0.02$ ). This may be due to the inclusion of the OT-APST's subscale of left/right aspects which are absent in the RPAB item. Another factor for the weak correlation may be that the RPAB Body Image Self-Identification subscale includes visuomotor integration skills as well as body scheme as the patient must imitate what the examiner does. This could further explain the high correlation (rho $=0.624$ ) between the RPAB Body Image Self-Identification and the OT-APST - Constructional Skills subscale in which the patient needs to copy a visual model using visuomotor skills. In previous research by Brown et al. ${ }^{20}$, the OT-APST Body Scheme subscale also significantly correlated with the Cognistat Constructional Ability (rho = 0,357).

\section{Unilateral Neglect}

The OT-APST Unilateral Neglect subscale includes the Clock, House, Handwriting, Reading and Telling the Time items. The DLOTCA Spatial Perception domain ( $r h o=0,557)$, and Visuomotor Construction domain ( $r h o=0,590)$ significantly correlated with the OT-APST Unilateral subscale. The DLOTCA Visuomotor Construction domain includes the Copy Geometric Forms, 2D Construction, Pegboard, Coloured Block Design, Plain Block Design, Puzzle and Clock items. It was expected that the OT-APST Unilateral Neglect subscale and the DLOTCA Visuomotor Construction domain would correlate as both items include a clock item. These results are similar to those reported by Cooke et al. ${ }^{12}$, where they found that the Unilateral Neglect subscale had the highest correlations with the LOTCA Puzzle and Clock when summed.

When the OT-APST Unilateral Neglect subscale is compared to the RPAB items evaluating inattention i.e. the Right/Left Copying Words $(r h o=0,664)$ and Right/Left Copying Shapes $(r h o=0,725)$ these items strongly correlated with the OT-APST Unilateral subscale. The RPAB Cancellation item which also evaluates unilateral neglect, however did not meet the cut-off point for a significant correlation $(r h o=0,5 \mid 4)$.

The OT-APST Unilateral Neglect subscale again is an added sum of items whilst the DLOTCA and the RPAB did not have an added sum for these items. This could contribute to some of the differences observed.

\section{Constructional Skills}

The OT-APST Constructional Skills subscale includes the following items: Clock and House, 2-Dimensional (2D) Construction and 3-Dimensional (3D) Construction items.

As expected, the OT-APST Constructional Skills subscale correlated very strongly with the DLOTCA Visuomotor Construction domain $($ rho $=0,903)$. Cooke et al. ${ }^{12}$, also found a significant correlation between the LOTCA Visuomotor Organisation Skills and the OT-APST Constructional Skills subscale.

The DLOTCA Visual Perception ( $r h o=0,639)$, Spatial Perception $($ rho $=0,636)$ and Praxis $(r h o=0,629)$ cognitive areas also strongly correlated with the OT-APST Constructional Skill subscale.

With the RPAB, the OT-APST Constructional Skills subscale strongly correlated with the RPAB 3D Copying Selection (rho= $0,707)$ and RPAB Cube Copying (rho $=0,76 \mathrm{I}$ ) as expected. Interestingly, it also strongly correlated with the Body Image item (rho= 0,728 ). Although the RPAB item is named 'Body Image', the way in which this item is assessed relates more to body scheme than body image. The RPAB Body Image items require the patient to assemble a face and a body ${ }^{29}$. This is consistent with the fact that a patient needs to know where his/her body is in space to correctly build anything (faces, puzzles) or imitate postures. The RPAB Body Image items also have a $2 \mathrm{D}$ construction element as the patient is expected to join the body parts to the trunk. This can further explain the correlation between the RPAB Body Image item and the OT-APST Constructional Skills subscale as a screening tool.

\section{Apraxia}

The OT-APST Apraxia items include: Facial Gesture, Wave Right Hand, Wave Left Hand, Stapler Manipulation, Pen Use for Writing and Handwriting ${ }^{27}$. The OT-APST Apraxia subscale and the DLOTCA Praxis cognitive area had low correlations ( $r$ ho $=0,436$ ). A possible reason for the low correlation can be that the DLOTCA evaluates performance on verbal command, imitation as well as with given objects. The motor imitation is also more complex than what is required by the OT-APST Apraxia items. Additionally, the DLOTCA included a pantomime item which was absent in the OT-APST as well as instruction with several steps. The OT-APST only evaluates performance on simple verbal command or imitation and object use. It is therefore important to note that apraxia/ dyspraxia will probably not be identified when using the OT-APST as a screening tool.

There were no significant correlations between the OT-APST Apraxia subscale and any of the RPAB items. This was however expected as there is no similar item on the RPAB.

\section{Acalculia}

In the OT-APST Acalculia (the tool only has one calculation item), the patient has to add and subtract simple single digit sums and two digit sums ${ }^{19}$. The numbers are arranged in a vertical orientation which makes it easier to calculate. Between the two reference tools, only the DLOTCA has an item on arithmetic i.e. the Verbal Mathematical Questions item which require the participants to read story-like scenarios, some use years (four digits) and other problems require higher cognitive/mathematical skills (e.g. "Joan was born before Liz and after Sharon. Who is the first born?25). In this study, the OT-APST Acalculia item strongly correlated with the DLOTCA Verbal Mathematical Questions (rho $=0,690)$. In previous research done by Cooke et al. ${ }^{13}$, the Acalculia subscale was not correlated with the LOTCA because the LOTCA did not have an item comparable with the OT-APST Acalculia. This is an important finding as acalculia can have a devastating effect on a person's day to day functioning in terms of handling money and managing time ${ }^{30}$. It is therefore possible to only use the OT-APST to identify acalculia in a patient with stroke and not necessary to use another evaluation.

\section{CONCLUSION}

This current research revealed that when compared to the DLOTCA and the RPAB, five of the six subscales of the OT-APST which were correlated had significant correlations with similar cognitive areas from the one or both reference tools. While the DLOTCA allows mediation, the OT-APST significantly correlated with the 'before mediation score' which is consistent with OT-APST being a static tool without mediation.

This study supports the initial research done by Cooke et $\mathrm{al}^{1{ }^{13}}$ in determining the construct validity of the OT-APST. The OT-APST subscales significantly correlated with either one or both reference tools except for the Apraxia subscale which did not correlate with either of the reference tools. Therapists will have to assess praxis in more detail when using the OT-APST as a screening tool.

Although the Functional Skills subscale was not compared to the DLOTCA or RPAB, it is important to note that this subscale is very useful in determining how functional the patient is given their impairments. This can be an added advantage of using the OT-APST.

The OT-APST shows construct validity when compared to the DLOTCA and RPAB. It is therefore recommended that the OTAPST can be used as a perceptual and cognitive screening tool for English speaking patients, with a stroke, in private and public health sector, in South Africa. This should however be done with caution since it has not been standardised on SA population.

\section{Limitations}

Translating the assessment tools from English to local languages was not possible for this study due to time and financial constraints. 
This meant that many of the black non-English speaking population have been excluded from this study thus affecting the generalisability of the research results to the larger South African population. Because of this the results are compromised by the small sample size (only 32 patients).

\section{Recommendations for further studies}

It is recommended further research be conducted on a larger sample size which is more representative of the South African population to allow generalisation of the results. The normative data for the African population further needs be established. It would be useful if the OT-APST could be translated to indigenous languages and validated so that a greater number of patients can benefit from the use of the assessments.

It is further recommended that clinicians utilise this instrument as this study confirmed the usefulness of this tool in identifying patients with visual perceptual deficits. Further research on all three of these tests is recommended to improve the body of knowledge in SA regarding the use of perceptual/cognitive assessment instruments.

\section{REFERENCES}

I. Beaglehole R, Bonita R, Horton R, et al. Priority actions for the non-communicable disease crisis. The Lancet. 201 I; 377: I438-47.

2. Mathers C, Fat DM and Boerma JT. The global burden of disease: 2004 update. World Health Organization; 2008.

3. Nojilana B, Bradshaw D, Pillay-van Wyk $\mathrm{V}$, et al. Emerging trends in non-communicable disease mortality in South Africa, 1997-2010. South African Medical Journal. 2016; 106: 477-84.

4. Connor M. Prevalence of stroke survivors in rural South Africa. Stroke. 2004; 35: 627-32.

5. Mercier L, Audet T, Hébert R, Rochette A and Dubois M-F. Impact of motor, cognitive, and perceptual disorders on ability to perform activities of daily living after stroke. Stroke. 200 I; 32: 2602-8.

6. Srikanth VK, Thrift AG, Saling MM, et al. Increased Risk of Cognitive Impairment 3 Months After Mild to Moderate First-Ever Stroke A Community-Based Prospective Study of Nonaphasic EnglishSpeaking Survivors. Stroke. 2003; 34: II 36-43.

7. Tatemichi T, Desmond D, Stern Y, Paik M, Sano M and Bagiella E. Cognitive impairment after stroke: frequency, patterns, and relationship to functional abilities. Journal of Neurology, Neurosurgery \& Psychiatry. 1994; 57: 202-7.

8. Pylyshyn Z. Is vision continuous with cognition?: The case for cognitive impenetrability of visual perception. Behavioral and brain sciences. 1999; 22: 34I-65.

9. Zinn S, Dudley TK, Bosworth HB, Hoenig HM, Duncan PW and Horner RD. The effect of poststroke cognitive impairment on rehabilitation process and functional outcome. Archives of physical medicine and rehabilitation. 2004; 85: 1084-90.

10. Katz N, Itzkovich M, Averbuch S and Elazar B. Loewenstein Occupational Therapy Cognitive Assessment (LOTCA) battery for brain-injured patients: reliability and validity. American Journal of Occupational Therapy. 1989; 43: 184-92.

II. Jandrell A, Engelbrecht $C$ and Gibb J. Occupational Therapy Assessment of visual perception in South African Adult Patients with Acquired brain Injury: A pilot study. BSc Occupational Therapy Research Report, Department of Occupational Therapy, University of the Witwatersrand; 2013.

12. Cooke DM, McKenna K, Fleming J and Darnell R. Construct and ecological validity of the occupational therapy adult perceptual screening test (OT-APST). Scandinavian Journal of Occupational Therapy. 2006; 13: 49-61.

13. Whiting S, Lincoln N, Bhavnani G and Cockburn J. RPAB: Rivermead Perceptual Assessment Battery. NFER-NELSON Publishing Company; 1985.

14. Bonita R, Beaglehole R and Kjellström T. Basic epidemiology. World Health Organization. 2006: 212.

15. Strong K, Wald N, Miller A and Alwan A. Current concepts in screening for noncommunicable disease: World Health Organization Consultation Group Report on methodology of noncommunicable disease screening. Journal of Medical Screening. 2005; 12: 12-9.

16. Cooke DM, McKenna K, Fleming J and Darnell R. Criterion validity of the occupational therapy adult perceptual screening test (OTAPST). Scandinavian Journal of Occupational Therapy. 2006; 13: 38-48.

17. Brown T. Construct validity: A unitary concept for occupational therapy assessment and measurement. Hong Kong Journal of Occupational Therapy. 2010; 20: 30-42.

18. Cooke D. The Occupational Therapy Adult Perceptual Screening Test administration manual. Brisbane: Function for Life; 2005.

19. Cooke DM, McKenna K and Fleming J. Development of a standardized occupational therapy screening tool for visual perception in adults. Scandinavian Journal of Occupational Therapy. 2005; 12 : 59-7I.

20. Brown T, Mapleston J and Nairn A. Convergent validity of the Occupational Therapy Adult Perceptual Screening Test (OT-APST) with two other cognitive-perceptual tests. The British Journal of Occupational Therapy. 201 I; 74: 562-72.

21. Elazar B, Itzkovich M and Katz N. Geriatric version: Loewenstein Occupational Therapy Cognitive Assessment (LOTCA-G) battery. Pequannock, NJ: Maddak; 1996.

22. Association AER, Association AP and Education NCoMi. Standards for educational and psychological testing. American Educational Research Association; 1999.

23. Kiernan R, Mueller J and Langston J. Neurobehavioral Cognitive Status Examination (Cognistat). Fairfax, CA: Northern California Neurobehavioral Group; 1983.

24. Itzkovich M, Elazar B and Averbuch S. Loewenstein occupational therapy cognitive assessment (LOTCA) manual. Maddak Incorporated; 2000.

25. Katz N, Livni L, Erez AB and Averbuch S. Dynamic Loewenstein Occupational Therapy Cognitive Assess for Adults. Pequannock; 2011.

26. Katz N, Erez AB, Livni L and Averbuch S. Dynamic Loewenstein Occupational Therapy Cognitive Assessment: Evaluation of potential to change in cognitive performance. The American Journal Occupational Therapy. 2012; 66: 207-14.

27. Kielhofner G. Research in occupational therapy: Methods of inquiry for enhancing practice. FA Davis; 2006.

28. Cooke D, McKenna K and Fleming J. Development of a standardised occupational therapy screening tool for visual perception in adults. Scandinavian Journal of Occupational Therapy. 2005; I2: 59-7I.

29. O'Brien J, Williams H, Case-Smith J and O'Brien J. Application of motor control/motor learning to practice. Occupational therapy for children. 20I0; 6: 245-74.

30. Basso A, Caporali A and Faglioni P. Spontaneous recovery from acalculia. Journal of the International Neuropsychological Society. 2005; 11: 99-107.

Corresponding author

Fadzai Razemba

fadzair@gmail.com 